\title{
Prioritizing operation strategies of companies using fuzzy AHP and importance-performance matrix
}

\author{
Mohamad Amin Kaviani $^{\mathrm{a}^{*}}$, Mehdi Abbasi ${ }^{\mathrm{b}}$, Mohamad Mehdi Yusefi ${ }^{\mathrm{b}}$ and Mohsen Zareinejad $^{\mathrm{a}}$
}

\author{
${ }^{a}$ Young Researchers and Elite Club, Shiraz Branch, Islamic Azad University, Shiraz, Iran \\ ${ }^{b}$ Department of Industrial engineering, Shiraz Branch, Islamic Azad University, Shiraz, Iran \\ C H R O N I C L E \\ Article history: \\ Received October 15, 2013 \\ Accepted January 24, 2014 \\ Available online \\ March 62014 \\ Keywords: \\ Operation strategy \\ Cement industry \begin{abstract}
A B S T R A C T
One of the most important steps to build an appropriate business unit is to setup a suitable longterm strategy. A good strategy helps organization take better advantage of the existing resources and improve the performance of the firm. This paper presents a hybrid method consists of importance-performance analysis combined with fuzzy analytical hierarchy process to determine different operating strategies to increase the performance of a cement industry in Iran. The results indicate that being competitive is number one priority followed by fast delivery, quality product, dependability, cost of production and flexibility.
\end{abstract}

Importance-performance matrix

Analytical hierarchy process

\section{Introduction}

Strategic planning plays essential role in development of all business organizations and there are several methods for measuring the performance of firms such as performance metric, which determines an organization's behavior and performance (Slack, 1994; Slack \& Lewis, 2002; Slack et al., 2010; Pinheiro de Lima et al., 2010). There are also methods based on Kano model for measuring the performance of organizations (Wu et al., 2010; Tontini \& Picolo, 2013). Performance metrics compute of an organization's activities and performance by supporting a range of stakeholders' needs. While traditionally many metrics are finance based, concentrating on the performance of the firms, metrics may also concentrate on the performance against customer's needs and values. In project management, performance metrics are applied to evaluate the health of the project by measuring of seven criteria including safety, time, cost, resources, scope, quality, and actions. According to Matzler et al. (2004) Importance-Performance analysis (IPA) is a two-dimensional grid based on customer-perceived importance of quality attributes and attribute performance to derive strategies for satisfaction management.

\footnotetext{
* Corresponding author

E-mail addresses: aminkaviani1366@yahoo.com (M. A. Kaviani) 
The method has become popular among practitioners. Hajirezaie and Moattar Husseini (2009) implemented Importance-Performance (I-P) matrix (Martilla \& James, 1977) in formulating manufacturing strategy by applying a quantitative method to evaluate the effectiveness of the strategic decisions at different levels of manufacturing strategy by using a fuzzy model (Chang, 1996; Vahidnia et al., 2008) to quantify the measure of the matrix. Deng (2007) provided a revised Importance-Performance analysis (IPA), which integrates three-factor theory concept, partial correlation analysis and natural logarithmic transformation and applied the model on a Taiwanese hot springs tourism case to present the implementation of the proposed revised IPA. He obtained the efficiency and the appropriate action direction for each satisfaction attribute by implementing the revised IPA, which enables business managers to reach a competitive advantage.

Hu et al. (2009, 2011) presented a new decision-making method, which exploits the back-propagation neural network (BPNN) to build quality characteristics and the hidden essential integral satisfaction assumptions. They applied the decision making trial and evaluation laboratory (DEMATEL) to calculate the causal relationship and extent of mutual influence among the qualities to modify the importance of the quality characteristics and detect the core Order-Winners and Qualifiers problems. The method modified the quality importance and improved the IPA model ranking and resolved difficult practical problems with fewer resources. The implementation of the study was demonstrated using Taiwan industrial computer, working in conjunction with IPA models built with BPNN and DEMATEL to observe its application and effect.

Khan and Rahman (2013) identify the critical criteria for the assessment of suppliers in foreign-aid funded procurement in Bangladesh based on a sample of executing agency executives, donor agency executives and supplying organization executives. The results indicated that, to provide better service, suppliers should assign tasks to the knowledgeable sales personnel. They also need to provide better warranties with well-known branded products, and make sure about a reliable level of quality. The supplier organizations need to apply a high quality management system, which allows prompt responses to reach and the provision of services without buyers having to follow up. IPA models can be integrated with other popular techniques such as analytical hierarchy process (Saaty, 1988) to provide more comprehensive results (Pak, 2013). Pezeshki et al. (2009) provided a systematic approach to investigate the asymmetric relationship between performance of service attributes and customer satisfaction through a case study in the mobile telecommunication industry. The results indicated that there was a dynamic relationship between service attributes and overall customer satisfaction. Prajogo and McDermott (2011) investigated the ten competitive dimensions of service based on relative importance and contribution to business performance, using the ImportancePerformance Analysis (IPA) matrix. They reported that customer retention and productivity needed to be taken care of, while innovation and speed may receive a lower priority.

\section{The proposed study}

This paper presents a hybrid method to determine different strategies to increase the performance of a cement industry in Iran. The proposed study uses IPA technique with the following steps,

1. Establishing critical processes/customer requirements,

2. Identifying specific, quantifiable outputs of work,

3. Establishing targets against which results can be scored.

The study also uses fuzzy AHP to measure the relative importance of one alternative over another one (See Fig. 1). The study has been applied on one of Iranian cement unit called Fars. As we can observe from Fig. 1, three cement firms A, B and C are measured based on five criteria including quality, cost, flexibility, speed and dependability. The study has gathered insights from 38 main customers and 44 retail customers. All questions of the survey were designed in Likert 1-9 scale where 1 
represents the highest degree of importance and 9 indicates the lowest degree of importance (Wheelwright \& Hayes, 1985).



Fig. 1. The proposed case study

Table 1 shows details of mean scores given to Fars unit compared with competitors firms named A, B and C.

\section{Table 1}

Mean Values of Importance and Performance

\begin{tabular}{lcccc} 
& & \multicolumn{3}{c}{ Mean value of performance } \\
\cline { 3 - 5 } Competitive priority & Mean value of Importance & A & B & C \\
\hline Quality & 1.78 & 1.25 & 3.84 & 2.55 \\
Cost & 4.12 & 4.18 & 4.12 & 4.36 \\
Flexibility & 5.44 & 5.35 & 4.02 & 5.15 \\
Speed & 2.12 & 3.75 & 2.25 & 2.15 \\
Dependability & 3.87 & 2.36 & 3.45 & 3.65 \\
\hline
\end{tabular}

The results of Table 1 indicate that quality is number one important factor followed by speed, dependability, flexibility and cost. In addition, Table 2 shows priorities of I-P matrix versus AHP.

Table 2

Priorities of Importance-Performance Matrix versus AHP

\begin{tabular}{ccc}
\hline Intensity of importance & Importance-performance matrix & AHP \\
\hline Extremely more importance & 1 & 9 \\
Very strong importance & 3 & 7 \\
Strong importance & 5 & 5 \\
Moderate importance & 7 & 3 \\
Equal importance & 9 & 1 \\
\hline
\end{tabular}

\section{The results}

In this section, we present details of our findings on analyzing cement unit based on IP matrix using fuzzy AHP method. Based on the results of Table 1 and Table 2, we present details of IP matrix in Fig. 2 as follows, 


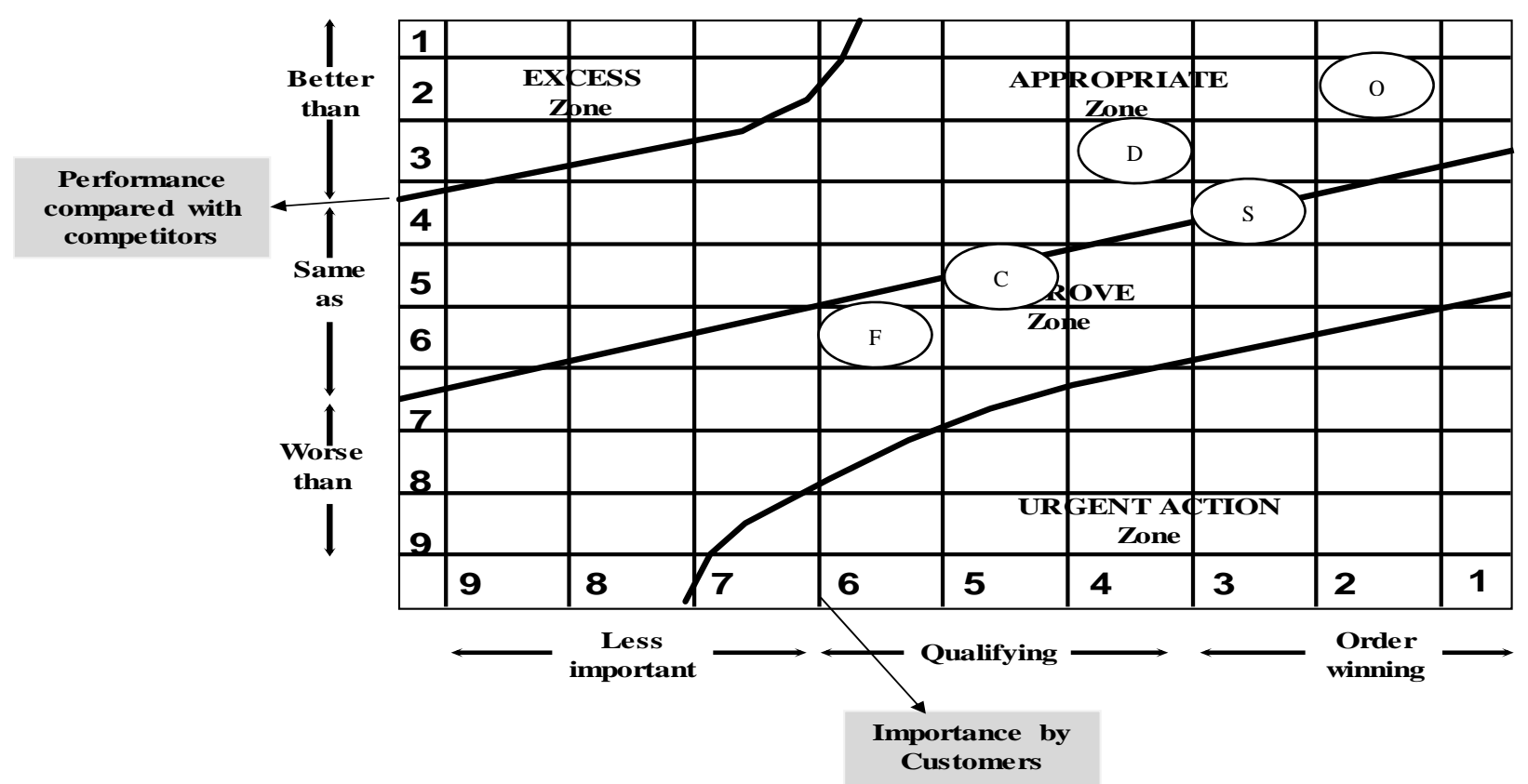

Fig. 2. The Importance-Performance Matrix of firm A

In Fig. 2, quality (Q) is positioned in highest level followed by dependability (D), speed (S), cost (C) and flexibility (F). Similarly, Fig. 3 shows IP matrix results for firm B.



Fig. 3. The Importance-Performance Matrix of firm B

The results of Fig. 3 indicate that dependability, speed and quality of firm B are in similar positions in terms of performance compared with competitors. In addition, quality is in good position in this firm. Finally, Fig. 4 shows details of our investigation for firm C. Now the proposed study of this paper uses fuzzy method to convert linguistic terms into regular numbers and Table 3 shows details of triangular numbers. Quality is an order-winner factor and the most important factor. In addition, speed of delivery is important and company A has the best operation strategy because of high performing in Quality and Speed(order winner factors).Based on Figs. 2-4, each company which can perform well in order winner factors, has better operation strategy. 
Table 3

The relative importance of all criteria

\begin{tabular}{cccc}
\hline Membership function & Definition & Fuzzy number & Intensity of importance \\
\hline$(8,9,10)$ & Extremely more importance(EMI) & $\tilde{9}$ & 1 \\
$(6,7,8)$ & Very strong importance (VSI) & $\tilde{7}$ & 3 \\
$(4,5,6)$ & Strong importance (SI) & $\tilde{5}$ & 5 \\
$(2,3,4)$ & Moderate importance (MI) & $\tilde{3}$ & 7 \\
$(1,1,2)$ & Equal importance (EI) & $\tilde{1}$ & 9 \\
\hline
\end{tabular}

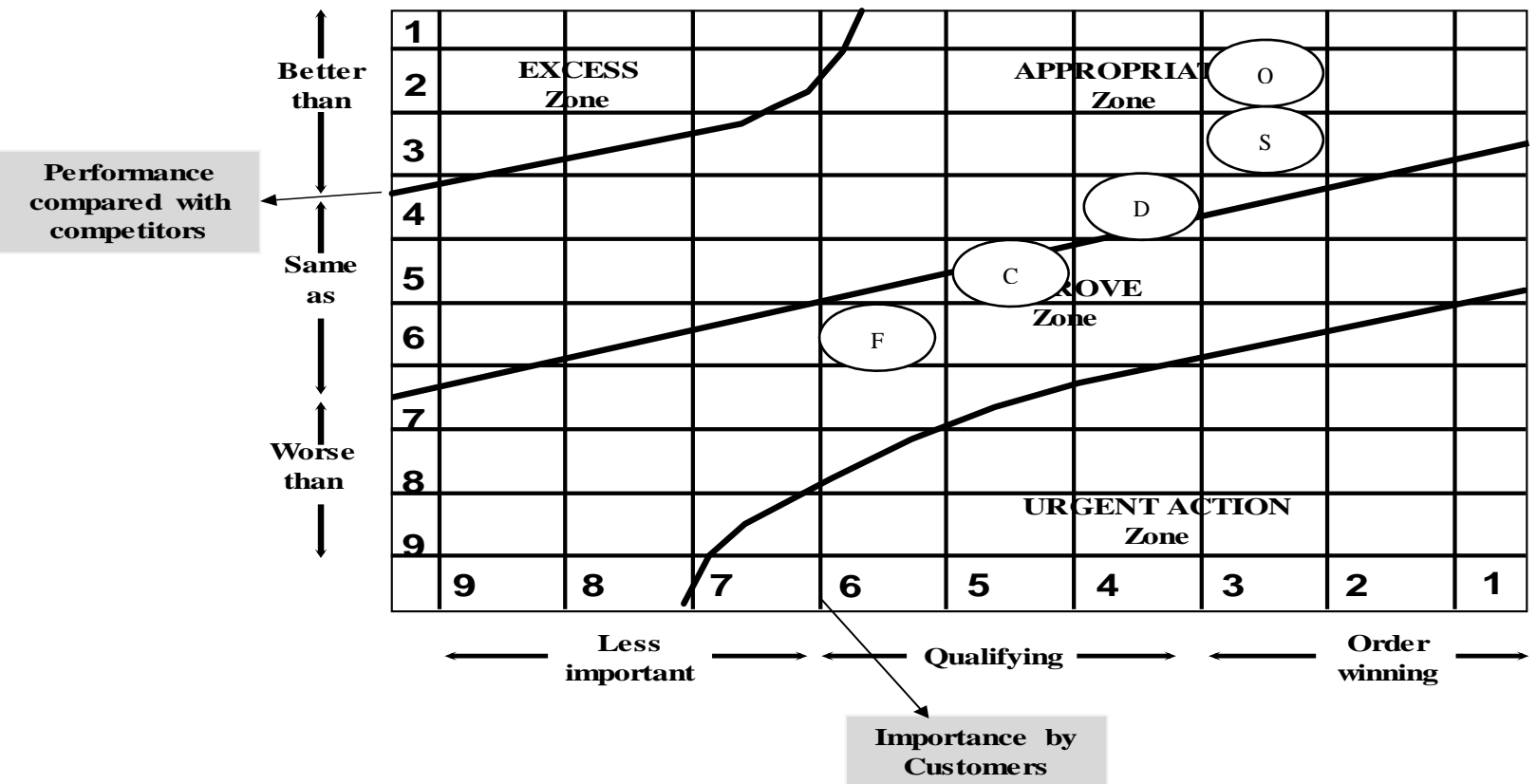

Fig. 4. The Importance-Performance Matrix of firm C

Based on the numbers of Table 3, fuzzy AHP (Wang et al., 2007; Duran \& Aguilo, 2008) is performed and Table 4 shows details of our findings. The local weight is calculated as $\mathrm{WG}=(0.11$, $0.21,0.09,0.34,0.24)$. Finally, Table 5 shows details of our ranking for three firms.

\section{Table 4}

The summary of fuzzy AHP

\begin{tabular}{lccccc}
\hline & Cost & Dependability & Flexibility & Quality & Speed of delivery \\
\hline Cost & 1 & $(1 / 4,1 / 3,1 / 2)$ & $(1,1,2)$ & $(1 / 4,1 / 3,1 / 2)$ & $(1 / 4,1 / 3,1 / 2)$ \\
Dependability & $(2,3,4)$ & 1 & $(2,3,4)$ & $(1 / 4,1 / 3,1 / 2)$ & $(1,1,2)$ \\
Flexibility & $(1 / 2,1,1)$ & $(1 / 4,1 / 3,1 / 2)$ & 1 & $(1 / 6,1 / 5,1 / 4)$ & $(1 / 4,1 / 3,1 / 2)$ \\
Quality & $(2,3,4)$ & $(2,3,4)$ & $(4,5,6)$ & 1 & $(1,1,2)$ \\
Speed of delivery & $(2,3,4)$ & $(1 / 2,1,1)$ & $(2,3,4)$ & $(1 / 2,1,1)$ & 1 \\
\hline
\end{tabular}

\section{Table 5}

The summary of ranking firms

\begin{tabular}{ccccccc}
\hline & Cost & Dependability & Flexibility & Quality & Speed & Alternative WG \\
\hline Weight & 0.11 & 0.21 & 0.09 & 0.34 & 0.24 & \\
A & 0.29 & 0.42 & 0.28 & 0.45 & 0.26 & 0.36 \\
B & 0.37 & 0.30 & 0.40 & 0.20 & 0.38 & 0.29 \\
C & 0.34 & 0.28 & 0.32 & 0.35 & 0.36 & 0.33 \\
\hline
\end{tabular}

\section{Conclusion}

In this paper, we have presented an empirical investigation to measure the relative performance firms in cement industry using Importance-Performance analysis. The proposed study has applied fuzzy 
analytical AHP method to measure the relative importance of various criteria and they were ranked, accordingly. The results of this survey have been discussed among some experts and some necessary actions have been accomplished to improve the performance of the case study.

\section{References}

Chang, D. Y. (1996). Applications of the extent analysis method on fuzzy AHP. European Journal of Operational Research, 95(3), 649-655.

Deng, W. (2007). Using a revised importance-performance analysis approach: The case of Taiwanese hot springs tourism. Tourism Management, 28(5), 1274-1284.

Duran, O. \& Aguilo, J. (2008). Computer-aided machine-tool selection based on a Fuzzy-AHP approach. Expert Systems with Applications, 34, 1787-1794.

Hajirezaie, M., \& Husseini, S. M. (2009). Evaluating the effectiveness of strategic decisions at various levels of manufacturing strategy: A quantitative method. World Applied Sciences Journal, 6(2), 248-257.

Hu, H. Y., Lee, Y. C., Yen, T. M., \& Tsai, C. H. (2009). Using BPNN and DEMATEL to modify importanceperformance analysis model-A study of the computer industry. Expert Systems with Applications, 36(6), 9969-9979.

Hu, H. Y., Chiu, S. I., Cheng, C. C., \& Yen, T. M. (2011). Applying the IPA and DEMATEL models to improve the order-winner criteria: A case study of Taiwan's network communication equipment manufacturing industry. Expert Systems with Applications, 38(8), 9674-9683.

Khan, S., \& Rahman, S. (2013). An importance-performance analysis for supplier assessment in foreign-aid funded procurement. Benchmarking: An International Journal, 21(1), 1-1.

Martilla, J. A., \& James, J. C. (1977). Importance-performance analysis. Journal of Marketing, 41(1).

Matzler, K., Bailom, F., Hinterhuber, H. H., Renzl, B., \& Pichler, J. (2004). The asymmetric relationship between attribute-level performance and overall customer satisfaction: a reconsideration of the importanceperformance analysis. Industrial Marketing Management, 33(4), 271-277.

Pak, R. J. (2013). Combining importance-performance analysis with analytic hierarchy process for enhancing satisfaction. Journal of Advanced Management Science, 1(4).

Pezeshki, V., Mousavi, A., \& Grant, S. (2009). Importance-performance analysis of service attributes and its impact on decision making in the mobile telecommunication industry. Measuring Business Excellence, 13(1), 82-92.

Pinheiro de Lima, E., Gouvea da Costa, S. E., Siqueira Ferreira, P. G., \& Angelis, J. (2010). Operations strategy and performance measurement roles. In Proceedings of the 21th Annual Production and Operations Management Society Conference (pp. 015-0710).

Prajogo, D. I., \& McDermott, P. (2011). Examining competitive priorities and competitive advantage in service organisations using Importance-Performance Analysis matrix. Managing service quality, 21(5), 465-483.

Saaty, T. L. (1988). What is the analytic hierarchy process? (pp. 109-121). Springer Berlin Heidelberg.

Slack, N. (1994). The importance-performance matrix as a determinant of improvement priority. International Journal of Operations \& Production Management, 14(5), 59-75.

Slack, N., \& Lewis, M. (2002). Operations strategy. Pearson Education.

Slack, N., Chambers, S., \& Johnston, R. (2010). Operations management. Pearson Education.

Tontini, G., \& Picolo, J. D. (2013). Identifying the impact of incremental innovations on customer satisfaction using a fusion method between importance-performance analysis and Kano model. International Journal of Quality \& Reliability Management, 31(1), 32-52.

Vahidnia, M. H., Alesheikh, A., Alimohammadi, A., \& Bassiri, A. (2008). Fuzzy analytical hierarchy process in GIS application. The International Archives of the Photogrammetry, Remote Sensing and Spatial Information Sciences, 37(B2), 593-596.

Wang, L., Chu, J., \& Wu, J. (2007). Selection of optimum maintenance strategies based on a fuzzy analytic hierarchy process. International Journal of Production Economics, 107, 151-163.

Wheelwright, S. C., \& Hayes, R. H. (1985). Competing through manufacturing. Harvard Business Review, 63(1), 99-109

Wu, H. H., Tang, Y. T., \& Shyu, J. W. (2010). An integrated approach of Kano's model and ImportancePerformance Analysis in identifying key success factors. African Journal of Business Management, 4(15), 3238-3250. 